\title{
Altered emotionality, hippocampus-dependent performance and expression of NMDA receptor subunit mRNAs in chronically stressed mice ${ }^{\dagger}$
}

\author{
João Costa-Nunes $s^{1,2} *$, Olga Zubareva ${ }^{3} *$, Margarida Araújo-Correia ${ }^{1} *$, Andreia Valença ${ }^{1} *$, Careen A. Schroeter ${ }^{4}$, \\ Jodi L. Pawluski ${ }^{1,5}$, Julie Vignisse ${ }^{1,5}$, Hellen Steinbusch ${ }^{1}$, Denise Hermes ${ }^{1}$, Marjan Phillipines ${ }^{1}$, \\ Harry M. W. Steinbusch ${ }^{1}$, and Tatyana Strekalova ${ }^{1,2,4 *}$
}

\begin{abstract}
${ }^{1}$ Department of Neuroscience, School for Mental Health and Neuroscience, Maastricht University, Maastricht, the Netherlands, ${ }^{2}$ Institute for Hygiene and Tropical Medicine, New University of Lisbon and Centre of Environmental Biology, Lisbon University, Lisbon, Portugal, ${ }^{3}$ Institute of Experimental Medicine, Russian Academy of Medical Sciences, St. Petersburg, Russia, ${ }^{4}$ Maastricht Medical Centre in Annadal, Maastricht, the Netherlands, and ${ }^{5}$ GIGA Neuroscience, Liège University, Liège, Belgium
\end{abstract}

\section{Abstract}

$N$-Methyl-D-aspartate receptor (NMDAR)-mediated neurotransmission in the hippocampus is implicated in cognitive and emotional disturbances during stress-related disorders. Here, using quantitative RT-PCR, we investigated the hippocampal expression of NR2A, NR2B and NR1 subunit mRNAs in a mouse stress paradigm that mimics clinically relevant conditions of simultaneously affected emotionality and hippocampus-dependent functions. A 2-week stress procedure, which comprised ethologically valid stressors, exposure to a rat and social defeat, was applied to male C57BL/6J mice. For predation stress, mice were introduced into transparent containers that were placed in a rat home cage during the night; social defeat was applied during the daytime using aggressive CD1 mice. This treatment impaired hippocampusdependent performance during contextual fear conditioning. A correlation between this behavior and food displacement performance was demonstrated, suggesting that burrowing behavior is affected by the stress procedure and is hippocampus-dependent. Stressed mice $(n=22)$ showed behavioral invigoration and anomalous anxiolytic-like profiles in the O-maze and brightly illuminated open field, unaltered short-term memory in the step-down avoidance task and enhanced aggressive traits, as compared to non-stressed mice $(n=10)$. Stressed mice showed increased basal serum corticosterone concentrations, hippocampal mRNA expression for the NR2A subunit of the NMDAR and in the NR2A/NR2B ratio; mRNA expression of NR2B and NR1 was unchanged. Thus, stress-induced aberrations in both hippocampal-dependent performance and emotional abnormalities are associated with alterations in hippocampal mRNA NR2A levels and the NR2A/NR2B ratio and not with mRNA expression of NR2B or NR1.
\end{abstract}

\section{Keywords}

Burrowing behavior, contextual fear memory, hippocampus, $\mathrm{N}$-methyl-D-aspartate receptor, predator stress, social defeat

\section{History}

Received 30 June 2013

Revised 30 November 2013

Accepted 3 December 2013

Published online 19 December 2013

\section{Introduction}

$\mathrm{N}$-Methyl-D-aspartate receptor (NMDAR)-mediated neurotransmission is involved in the etiology of stress-related cognitive deficits and behavioral abnormalities (Cull-Candy et al., 2001). This particularly implicates altered expression of the two NR1 (GluN1) and two NR2 (GluN2) subunits (NR2A and NR2B) of NMDAR tetramers, which are the most abundant in the hippocampal formation, a brain structure that mediates stress-induced aberrations in both learning and

\footnotetext{
$\dagger$ Dedicated to the memory of my mentor Prof. Konstantin Sudakov who greatly contributed to the field and passed away in 2013.

*These authors equally contributed to this work.

Correspondence: Dr. Tatyana Strekalova, Department of Neuroscience, School for Mental Health and Neuroscience, Maastricht University, Universiteitssingel 40, NL 6229 ER Maastricht, the Netherlands. Tel: $+31 \quad 43 \quad 38 \quad 84$ 110. Fax: +31 $43 \quad 3671$ 096. E-mail: t.strekalova@maastrichtuniversity.nl
}

emotional behavior (Li \& Ju, 2012). Both NR2A and NR2B were shown to have distinct pharmacology and a role in the regulation of NMDAR, and have been suggested to be differentially involved in the mechanisms of learning and emotionality (Fleischmann et al., 2003; Li \& Tsien, 2009). A body of evidence has demonstrated the involvement of NR2A, NR2B and NR1 subunits in the neurobiology of neuropsychiatric conditions such as anxiety, psychosis, impulsivity, Alzheimer's disease and major depression (Davies et al., 2012; Geissler \& Lesch, 2011; Tsang et al., 2008).

Most experiments investigating the roles of NMDAR subunits in neuropsychiatric symptoms target selective subunits of this receptor using pharmacological and genetic manipulations that are frequently applied in vitro (Boyce-Rustay \& Holmes, 2006; Cui et al., 2013; Longordo et al., 2009). However, fewer studies have addressed the changes in NMDAR subunit expression in 
disease-modeling conditions. Understanding changes in relative-fold mRNA expression of NMDAR subunits in animal models of cognitive and emotional disturbances related to chronic stress is important for the identification of new pharmacological interventions and therapies that effectively alter glutamatergic transmission (Vignisse et al., 2013). Previous work on gene expression (Strekalova et al., 2011) has highlighted abnormal hippocampal expression of NMDAR subunits in mice subjected to repeated stressors. We have hypothesized that in male C57BL/6J mice, a novel 2-week stress procedure, comprising ethologically valid stressors, exposure to a rat and social defeat, results in concomitant cognitive, emotional and NMDA receptor expression abnormalities in the hippocampus. Thus, the current study specifically investigated the hippocampal relative-fold mRNA expression of NR2A, NR2B and NR1 subunits in the above-mentioned chronic stress procedure in mice that mimics clinically relevant situations of stress-related disturbances in learning and emotionality (Cline et al., 2012; Strekalova \& Steinbusch, 2010).

\section{Materials and methods}

\section{Animals and housing}

Male C57BL/6J and CD1 mice were 3 months old, Wistar rats of 3-5 months age were used for applying predator stress; mice and rats were provided by Harlan, the Netherlands and Charles River, France, respectively. Fourteen days before the behavioral experiments, mice were single housed under a reverse $12 \mathrm{~h}: 12 \mathrm{~h}$ light-dark cycle (lights on: 21:00h) in standard laboratory conditions $\left(22 \pm 1^{\circ} \mathrm{C}, 55 \%\right.$ humidity, food and water ad libitum). All experiments were carried out in accordance with the European Committees Council Directives and had been approved by the ethics committee of Maastricht University for animal research (CPV, DEC-UM 2009-109).

\section{Experimental conditions and study outline}

This study applied only ethological stressors to male C57BL/6J mice, for $14 \mathrm{~d}$, based on previous work (adapted from Cline et al., 2012; Couch et al., 2013). The stress procedure consisted of dark-cycle rat exposure between the hours of 09:00 $\mathrm{h}$ and 18:00 $\mathrm{h}$ and light-cycle application of a social defeat paradigm, combined with exposure to an aggressive CD1 mouse. Body weight and parameters of social behavior were determined 1 week before the chronic stress procedure in a social interaction test as described elsewhere (Strekalova et al., 2004). The experimental and control groups were balanced for these parameters. Ethological stressors were applied to a stress group for $14 \mathrm{~d}$, as described below. The control group received daily handling only. At the end of the stress experiment, $12 \mathrm{~h}$ after the application of the last stressor, short-term memory in the stepdown avoidance task (Vignisse et al., 2011) and aggressive behavior in a resident-intruder test (Strekalova et al., 2004) were investigated in stressed and control mice. At this time, body weight was also assessed. The next day (day 1), mice were tested in the elevated O-maze and food displacement tube tests (Strekalova \& Steinbusch, 2010). On days 2 and 3, respectively, contextual fear conditioning training and testing for recall (Vignisse et al., 2013) were performed.
The open-field testing was carried out on day 4 (under red light) and on day 5 (under white light). All behavioral tests were recorded on video.

We used a battery of behavioral tests based on previous literature (Calabrese et al., 2012). Although it is possible that the different behavioral tests may affect subsequent tests, previously published test batteries with similarly employed paradigms have revealed an absence of any testing effects in C57Bl/6J mice (Malatynska et al., 2012; Strekalova \& Steinbusch, 2009, 2010; Vignisse et al., 2011, 2013). Hence, we considered possible interfering effects of multiple behavioral test to be minimal in the current study.

A separate cohort of mice from both groups was preexposed to a mixture of $\mathrm{CO}_{2}$ and $\mathrm{O}_{2}$ and euthanized via cervical dislocation (according to Dutch law), for gene expression analysis $24 \mathrm{~h}$ after the termination of the stress procedure.

\section{Chronic stress procedure}

Rat exposure while in a small container

Mice were introduced into cylindrical containers, which were placed into a rat home cage for $15 \mathrm{~h}$ (overnight, from 18:00 $\mathrm{h}$ to 9:00h). Containers $(15 \mathrm{~cm} \times \varnothing 8 \mathrm{~cm})$ were made from customized transparent plastic with holes in the covers $(\varnothing<0.5 \mathrm{~cm})$. This ensured protection of the mouse from the rat, but allowed visual and odor contact. During the weekends, mice were kept in their home cages, situated on top of the rat cages.

\section{Social defeat stress}

Social defeat procedures took place during the dark phase of the light cycle (between 12:00 h and 16:00 h). To enable visual control by the experimenter over the resident-intruder confrontation, the test was carried out under red light. In a preliminary test, aggressive CD1 mice that were able to attack the counter-partners in less than $60 \mathrm{~s}$, without injuring them, were selected for this procedure; these mice were introduced into the home cages of mice from the stress group during social defeat sessions for $5 \mathrm{~min}$. During social defeat stress, test mice typically showed flight responses, submissive postures and vocalizations. Pairs of mice were carefully observed in order to prevent physical harm. In rare cases, aggressive mice were immediately removed from the cage of resident mice. After a 5-min period of social defeat, C57BL/6J mice were placed into small containers and put inside a CD1 mouse cage, where they stayed for a $3 \mathrm{~h}$-period. After the $3 \mathrm{~h}$ period, the 5 -min social defeat procedure was repeated. In order to randomize the procedure, the same pairs of C57BL/6J and CD1 mice were never put together.

\section{Behavioral procedures}

\section{Step-down passive avoidance model}

The step-down passive avoidance test was used as described elsewhere (Strekalova et al., 2001; Vignisse et al., 2011, 2013). The step-down apparatus (Evolocus LLC Tarrytown, NY and Technosmart, Rome, Italy) was a transparent plastic cubicle $(25 \mathrm{~cm} \times 25 \mathrm{~cm} \times 48 \mathrm{~cm})$ with a stainless-steel grid floor (33 rods $2 \mathrm{~mm}$ in diameter), onto which a square wooden 
platform $(7 \mathrm{~cm} \times 7 \mathrm{~cm} \times 1.5 \mathrm{~cm})$ was placed. The illumination strength was 25 lux. A shocker was used to deliver an alternating electric current $(\mathrm{AC}, 50 \mathrm{~Hz})$. In this paradigm, mice are trained to avoid an electric shock by staying on the platform above the grid floor. During the training session, mice were placed on the platform inside a transparent cylinder for $30 \mathrm{~s}$ to prevent them from stepping down immediately. After removal of the cylinder, the time until the mouse left the platform, with all four paws, was measured as baseline latency of step-down. Immediately after step-down, mice received a single electric foot shock $(0.5 \mathrm{~mA}, 2 \mathrm{~s})$ and were returned to their home cages. One hour later, during the recall trial session, mice were exposed to the apparatus again by being handled in the same way as in the training session; no foot shock was delivered. Latency of step-down with all four paws was measured until $180 \mathrm{~s}$ had elapsed.

\section{Elevated O-maze}

Testing on the elevated O-maze was carried out as described elsewhere (Strekalova et al., 2005). The O-maze consisted of a black circular path (runway width $5.5 \mathrm{~cm}, \varnothing=46 \mathrm{~cm}$ ) with two opposing compartments protected by walls made of polyvinyl-chloride (height $=10 \mathrm{~cm}$ ) and two open sectors of equal size. The maze was elevated $20 \mathrm{~cm}$ above the ground and illuminated from the top with red light. At the start of the testing session, mice were placed inside one of the two closed compartments. The test was recorded with a web camera. The latency to the first entry into the anxiety-related open arms of the maze, total number of entries into the open arms and total duration of time spent in open arms were scored for $5 \mathrm{~min}$.

\section{Food pellet displacement (burrowing) behavior in a tube test}

In order to further assess hippocampal function, all experimental groups were tested for burrowing behavior. Burrowing behavior, a tendency to displace small objects, e.g. small stones or food pellets, from a tube inside the home cage, is species-specific in mice and has been demonstrated to depend on an intact hippocampal formation. Using a paper tube (internal diameter $4 \mathrm{~cm}$, length $10 \mathrm{~cm}$ ), filled with 20 food pellets and placed in the middle of a mouse home cage, the latency to displacement of the first food pellet, time required to empty the tube, number of pellets removed after $1 \mathrm{~h}$ and $1 \mathrm{~h}$ $30 \mathrm{~min}$ were assessed in stressed and control mice during the dark phase (Strekalova \& Steinbusch, 2009, 2010). Time elapsed was $90 \mathrm{~min}$.

\section{Contextual fear-conditioning paradigm}

The contextual fear-conditioning test procedure was adapted from previously described protocols (Strekalova et al., 2003; Vignisse et al., 2013). The apparatus consisted of a transparent plastic cubicle $(25 \mathrm{~cm} \times 25 \mathrm{~cm} \times 50 \mathrm{~cm})$ with a stainlesssteel grid floor (33 rods $2 \mathrm{~mm}$ in diameter). A shocker was used to deliver an alternating electric current $(\mathrm{AC}, 50 \mathrm{~Hz} ; 0.7$ $\mathrm{mA}, 2 \mathrm{~s}$ ) after a 2-min acclimatization of a mouse to the chamber. After delivery of the current, the mouse was immediately placed back in the home cage. Freezing behavior was scored by visual observation during a test of memory recall that was carried out $24 \mathrm{~h}$ later. The occurrence of freezing behavior in the chamber was assessed every $10 \mathrm{~s}$ for
$180 \mathrm{~s}$; each 10-s score was assigned to a freezing or non-freezing period, and the percentage of time spent in freezing was calculated.

\section{Open field}

The open-field apparatus consisted of four square arenas $(25 \mathrm{~cm} \times 25 \mathrm{~cm} \times 40 \mathrm{~cm})$, made of wood covered with white resopal. Mice were put in the center of one of the four square open field arenas, and their behavior was video recorded for $10 \mathrm{~min}$. The open field was illuminated with white light (25 lux) or red light. Behavior was analyzed off-line using the Any-maze software (Stoelting Co, Wood Dale, IL). Among other parameters, time spent immobile was analyzed in the central (area $20 \times 20 \mathrm{~cm}$ ) and peripheral (remaining part of the apparatus) zones.

\section{Resident-intruder test}

The resident-intruder test procedure was performed as described elsewhere (Strekalova et al., 2004). In this paradigm, the $\mathrm{C} 57 \mathrm{BL} / 6 \mathrm{~J}$ mice were placed individually in an observation cage $(30 \mathrm{~cm} \times 60 \mathrm{~cm} \times 30 \mathrm{~cm})$ for $30 \mathrm{~min}$. Thereafter, a male CD1 mouse, which was group housed before the test, was introduced as an intruder to the same cage and left with the resident mouse for $8 \mathrm{~min}$. During the observation period, resident and intruder mice were scored for aggressive social behaviors. Latency of the first attack and number of attacks were scored.

\section{Brain dissection and blood collection}

On the day following the termination of the stress procedure, a cohort of mice from both groups was euthanized as described above, their hippocampi were dissected and trunk blood was collected for corticosterone evaluation.

\section{Corticosterone concentration}

To assay serum corticosterone, trunk blood was stored at $4{ }^{\circ} \mathrm{C}$ overnight and centrifuged at $10 \times g$ for $10 \mathrm{~min}$; the assay was performed as previously described (Pawluski et al., 2012). Serum was collected and stored a $-80^{\circ} \mathrm{C}$ until use. All samples were run in duplicate. For total serum corticosterone concentrations, a commercially available radioimmunoassay (RIA) kit for rat corticosterone from MP Biomedicals (corticosterone I25 for rats and mice, MP Biomedicals, LLC, Orangeburg, NY) was used. Average intra- and interassay coefficients of variation for all corticosterone assays were below $10 \%$. Assay sensitivity was $7.7 \mathrm{ng} / \mathrm{mL}$.

\section{RNA isolation and RT PCR}

RNA was extracted as previously described (Couch et al., 2013) using the RNeasy RNA extraction kit (Qiagen, Hilden, Germany) and first strand cDNA synthesis was performed using random primers and Superscript III transcriptase (Invitrogen, Darmstadt, Germany); $1 \mu \mathrm{g}$ total RNA was converted into cDNA. Quantitative RT-PCR (qPCR) for $N R 2 A, N R 2 B, N R 1$ genes and the housekeeping gene glyceraldehyde-3-phosphate dehydrogenase (GAPDH) was performed using TaqMan probes and the CFX96 Real-time System (BioRad, Hercules, CA). Cycling conditions and 
sequences of primers used are indicated in Table 1 of supplementary data. Results were normalized to GAPDH mRNA expression and calculated as relative-fold changes compared to control mice as described elsewhere (Couch et al., 2013). Results of the qPCR measurements were expressed as $\mathrm{Ct}$ values, where $\mathrm{Ct}$ is defined as the threshold cycle of PCR at which amplified product was $0.05 \%$ of normalized maximal signal. We used the comparative $\mathrm{Ct}$ method and computed the difference between the expression of the gene of interest and GAPDH expression in each cDNA sample (2- $\Delta \Delta \mathrm{Ct}$ method). Results are given as expressionfolds compared to the mean expression values in non-stressed control mice (Couch et al., 2013, adapted from Livak \& Schmittgen, 2001).

\section{Statistical analysis}

GraphPad Prism 5.00 (San Diego, CA) was used for analyses. A comparison of normally distributed independent variables was carried out using unpaired two-tailed $t$ tests. Independent measurements that were not normally distributed were analyzed via the non-parametric Mann-Whitney test, and repeated measurements were compared by the Wilcoxon nonparametric test. The Pearson test was applied for correlation analysis. The level of confidence was set at 95\% $(p<0.05)$.

\section{Results}

Stressed mice showed a significant loss of body weight compared to the control mice ( $p<0.0001, t=6.801, \mathrm{df}=21$; unpaired $t$ test; Figure 1A) and a significant elevation of circulating corticosterone concentration $(p=0.030, U=39$; Mann-Whitney test, Figure 1B), indicating a profound impact of the 2-week stress procedure. In comparison to control mice, the open-field activity of the stressed mice was significantly higher both in the peripheral $(p=0.040$, $U=61.00$, Mann-Whitney test) and even more notably, in the central zones $(p=0.011 ; U=73.50)$ of the apparatus, when white lighting was employed (Figure 1C), but not when activity was scored under red light $(p=0.15, U=68.00$ and $p=0.64, U=97.50$, respectively). There was a significantly lower latency to the first exit in the elevated O-maze ( $p=0.010, U=49.50$, Mann-Whitney test), increased time spent in the open arms $(p=0.020, U=55.50)$ and number of entries into the open arms $(p=0.028, U=58.50$; Figure 1D) in stressed versus control mice. Together, these data indicate differences in the brightly lit open field induced by stress: behavioral invigoration and an anomalous "anxiolytic-like", profile. In addition, chronically stressed mice displayed a significant increase in the number of attacks and no change in the latency to the first attack in the resident-intruder test $(p=0.049, t=1.698, \mathrm{df}=30$ and $p=0.12, t=1.78, \mathrm{df}=23$; unpaired $t$ test; Figure 1E).

Both stressed and control mice showed a significant increase in the latency of step down $1 \mathrm{~h}$ after training, in comparison to baseline latencies ( $p=0.033, W=-37.00$ and $p=0.05, W=-51.00$, respectively, Wilcoxon test). There was no significant difference between stressed and control mice in the latencies for step-down evaluated at baseline conditions ( $p=1.0, U=71.50)$ or $1 \mathrm{~h}$ after training $(p=0.98$, $U=71.00 ;$ Figure 2A), indicating similar scores of anxiety-like behavior and short-term memory in these groups. In the contextual fear-conditioning paradigm, stressed mice spent a significantly shorter time freezing during a recall session than the control group $(p=0.021, U=50.00$, MannWhitney test; Figure 2B), which demonstrates impaired hippocampus-dependent contextual memory in this group. Stressed mice showed no significant inhibition of burrowing behavior in comparison to the control group, as assessed by latency for the first pellet displacement $(p=0.18, U=73.00$; Figure 2C) and number of pellets displaced over time intervals of $0-60 \mathrm{~min}(p=0.14, U=53.50)$ and $60-90 \mathrm{~min}$ ( $p=0.34, U=47.50$, Mann-Whitney test). Nonetheless, there was a significant correlation between the two latter measures and contextual freezing $(r=0.36, p=0.046$ and $r=0.36$, $p=0.048$, respectively). There was no significant correlation between the duration of freezing and the latency for pellet displacement ( $r=-0.16, p=0.39$, Pearson correlation).

Concerning mRNA levels of NMDA receptor subunits in the hippocampus, in comparison to control mice, the stressed group had a significant increase in expression of NR2A ( $p=0.029, t=2.050, \mathrm{df}=15$, unpaired $t$ test; Figure 3A) and no significant change in the expression of NR2B $(p=0.27$, $t=0.6431$, df $=15$, Figure $3 \mathrm{~B})$. The ratio of NR2A/NR2B was significantly increased $(p=0.015, t=2.452, \mathrm{df}=13$; Figure $3 \mathrm{C}$ ) but the expression of the NR1 subunit was unaltered ( $p=0.64, t=0.4665, \mathrm{df}=14$; Figure 3D).

\section{Discussion}

In accordance with our hypothesis and in line with the literature (Calabrese et al., 2012; Cull-Candy et al., 2001; Fleischmann et al., 2003; Li \& Ju, 2012), the current study implicates altered expression of NMDAR subunits of the hippocampus in stress-induced deficits in both cognitive and emotional traits. The present study showed that in C57BL/6J mice, a 2-week ethological stress paradigm, comprised of exposure to a rat and social defeat, resulted in the impairment of contextual fear conditioning, as well as behavioral disinhibition in the open field test and increased aggressive behavior. These cognitive and emotional abnormalities were accompanied by increases in the hippocampal mRNA expression of the NR2A subunit of the NMDAR and in the NR2A/NR2B ratio, while the mRNA expression of NR2B and NR1 was unchanged.

A significant reduction in body weight and increase in basal serum corticosterone concentration of stressed mice demonstrated the impact of the 2-week stress procedure (Figure 1A, B). Stressed mice displayed behavioral hyperarousal under stressful testing conditions, as shown by a significant decrease in the time spent immobile in the central and peripheral parts of the brightly illuminated open field, but a lack of these changes during stress-free open field testing under red light (Figure 1C). Behavioral alterations of the stressed group in the open field illuminated with white light are in agreement with behavioral changes in these mice in the elevated O-maze. In the O-maze test, stressed mice showed a significant shortening of the latency to enter the open arms, an increase in the time spent and the number of entries into the open arms (Figure 1D). Together, these findings indicate that the stress procedure evoked anomalous "anxiolytic-like", 
(A) BODY WEIGHT

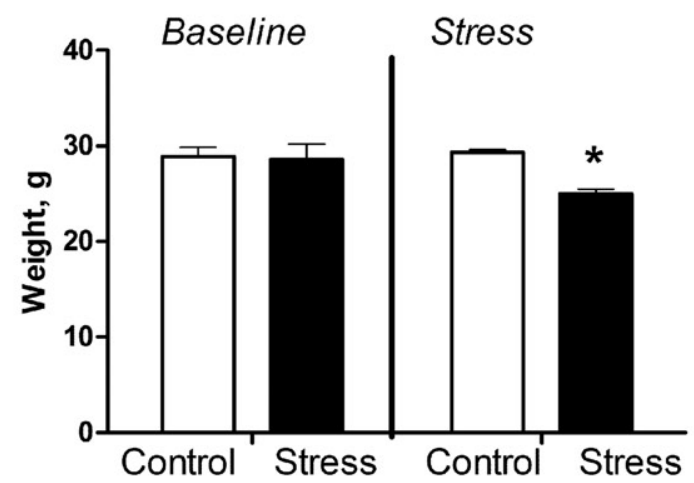

(C)

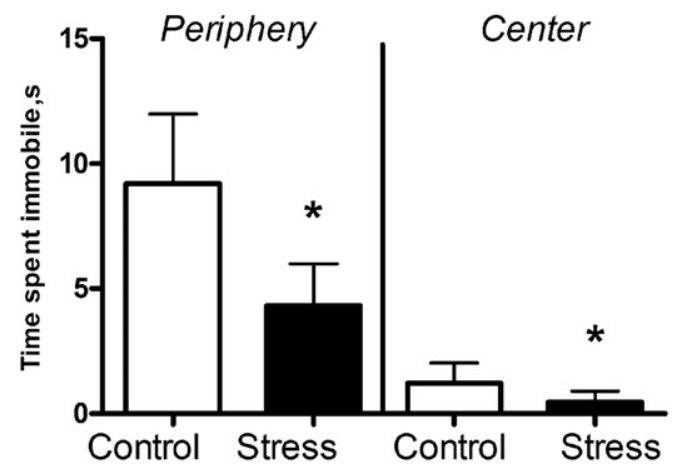

(B) PLASMA CORTICOSTERONE

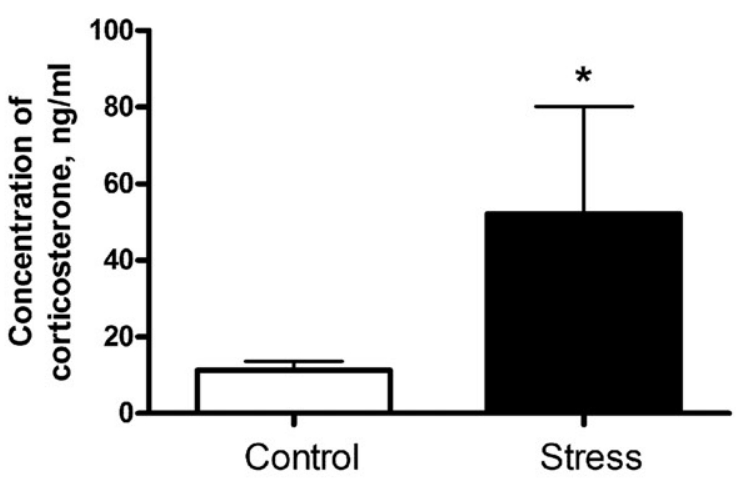

OPEN FIELD RED LIGHT

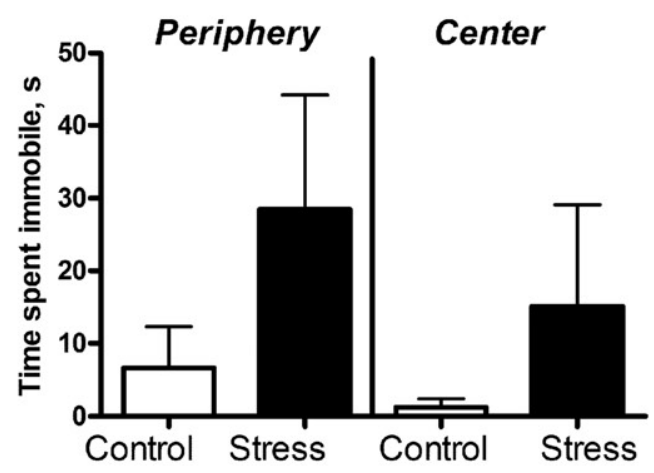

(D) ELEVATED O-MAZE
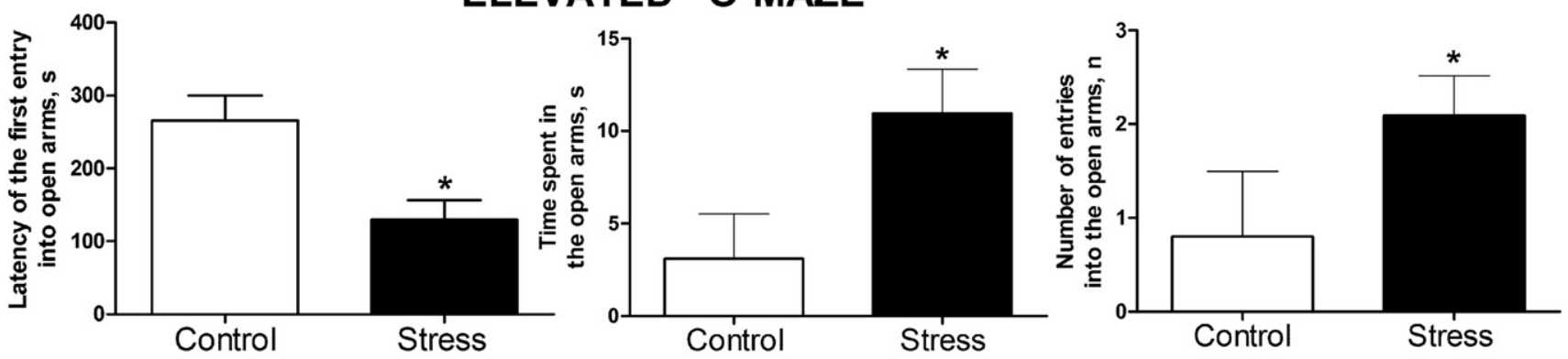

(E)

RESIDENT-INTRUDER TEST
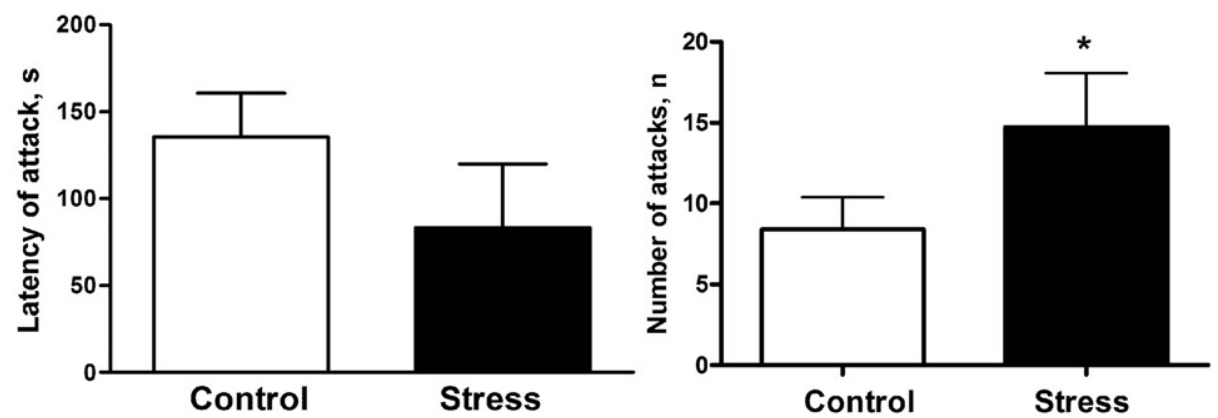

Figure 1. Exposure of mice to stressors for 2 weeks affects body weight, serum corticosterone and parameters of emotionality. (A) Weight loss and (B) increased serum corticosterone concentration in the stress group. (C) Stressed mice showed a reduced total time spent immobile at the periphery and in the center of the open field lit with white light. There were no significant differences in locomotor behavior between groups tested under red light. (D) Stressed mice displayed decreased latency of entries into the open arms, an increased time spent therein and increased number of entries. (E) Elevated aggressive behavior (number of attacks) in stressed mice. ${ }^{*} p<0.05$ versus control (A, E: unpaired $t$ test, B-D: Mann-Whitney test). Control group, $n=10$; stress group, $n=22$. All data are means \pm standard error of the mean (SEM). 
(A)

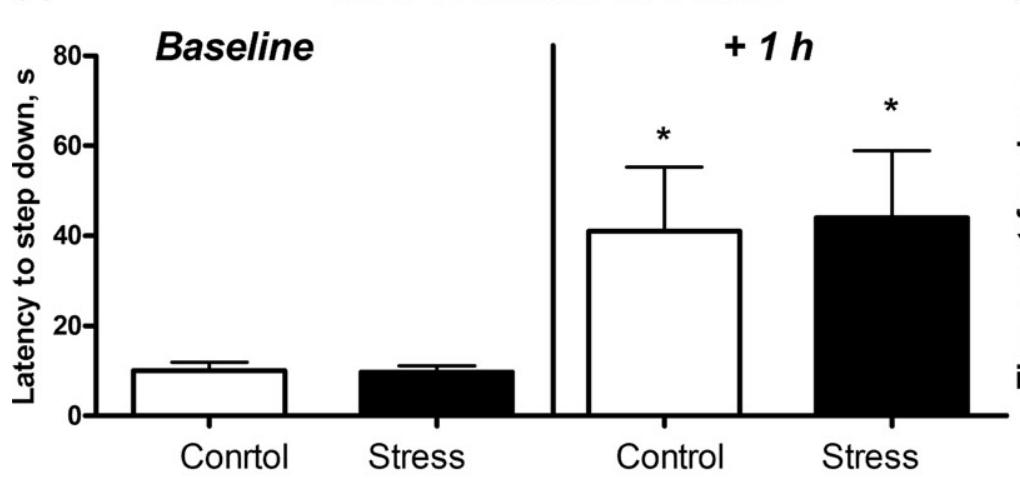

(B) FEAR CONDITIONING

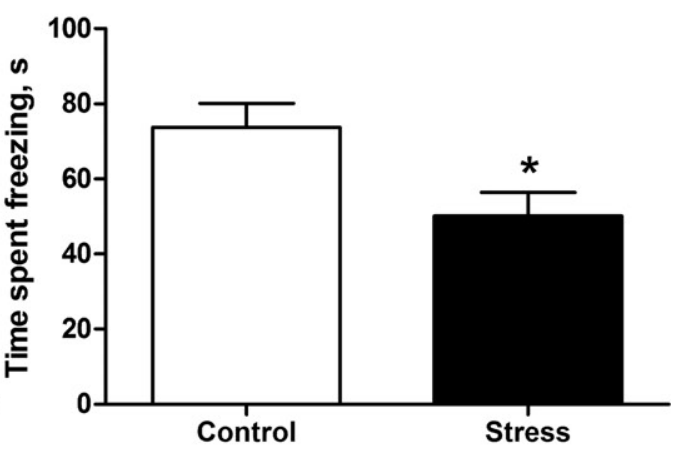

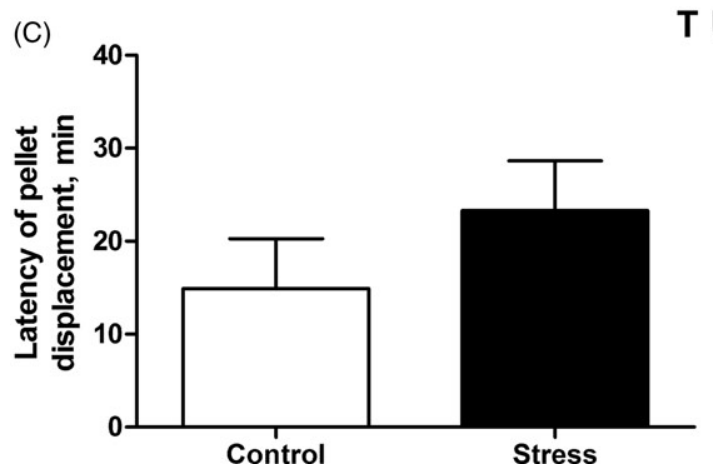

TUBE TEST

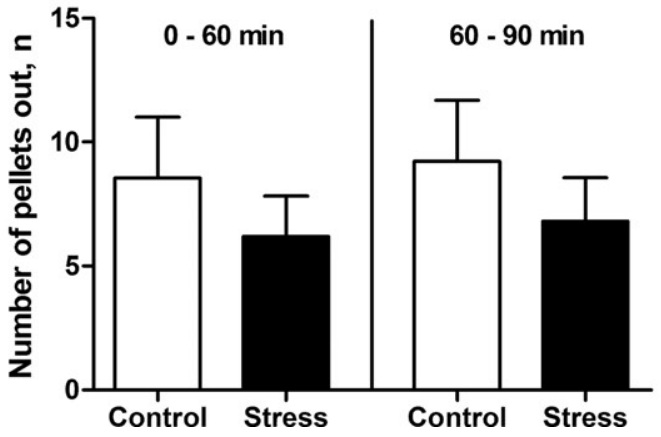

Figure 2. Hippocampus-dependent performance in stressed mice. (A) Stressed and control mice showed a significant increase in the latency for step down $1 \mathrm{~h}$ after training, in comparison to baseline latencies; ${ }^{*} p>0.05$ versus baseline, Wilcoxon test; there were no differences between groups. (B) Stressed mice spent a significantly shorter time freezing, during a recall session in the fear-conditioning paradigm; (C) there were no significant differences for latency to food displacement or number of pellets displaced at $0-60 \mathrm{~min}$ and $60-90 \mathrm{~min}$ in the tube test. * $p<0.05$ versus control; Mann-Whitney test. Control group, $n=10$; stress group, $n=22$. All data are means \pm the standard error of the mean (SEM).

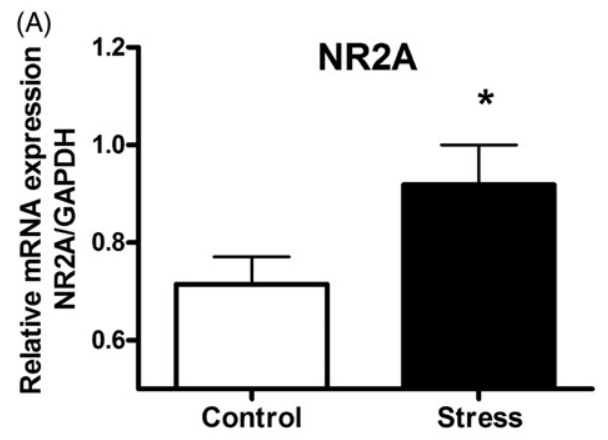

(B)
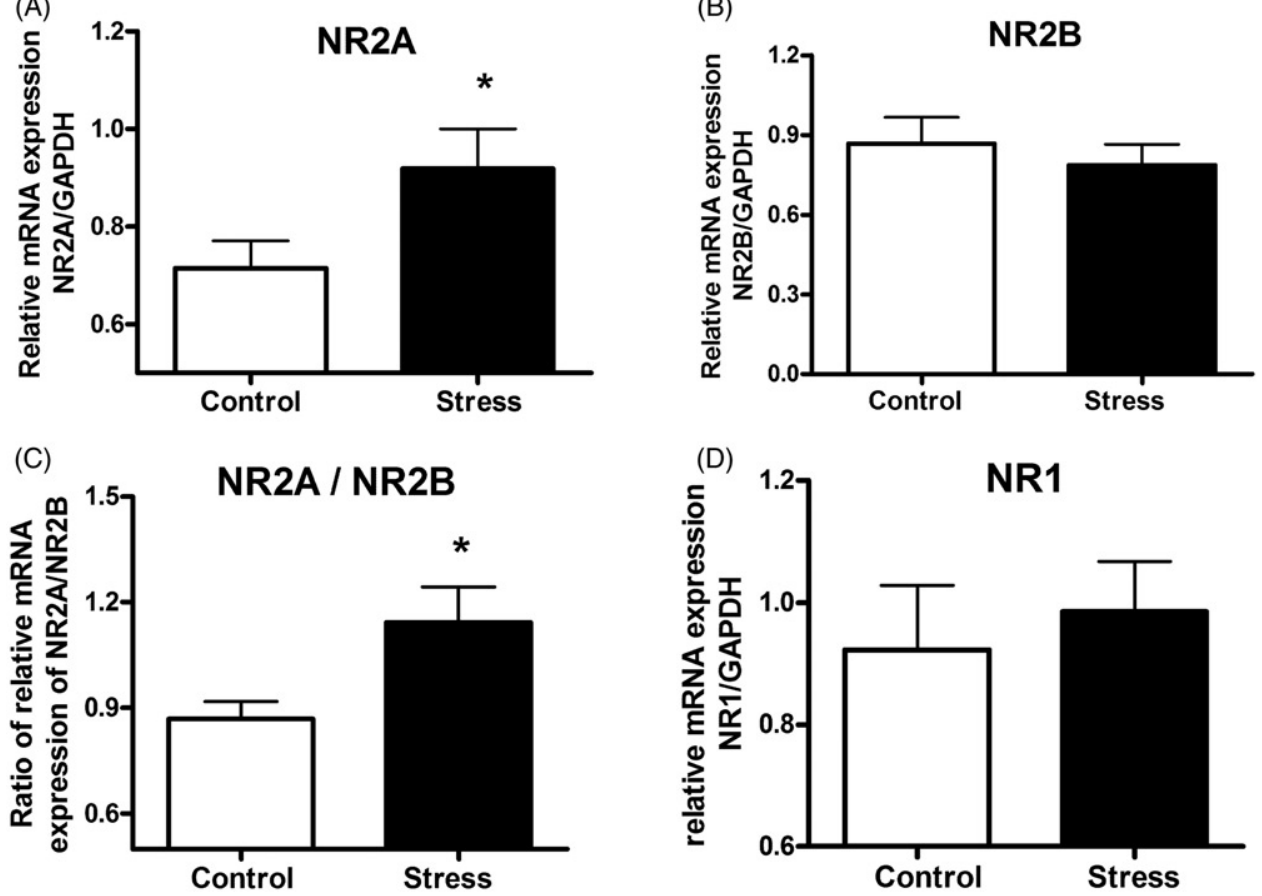

Figure 3. Hippocampal expression of mRNAs for $N$-methyl-D-aspartate receptor (NMDAR) subunits in stressed mice. In the stressed group, relative to controls: (A) mRNA expression of the NR2A subunit of the NMDAR was significantly greater; (B) mRNA expression of NR2B was not altered; (C) the ratio of mRNAs for NR2A/NR2B was significantly increased; (D) mRNA expression of the NR1 subunit of NMDAR was not altered; * $p<0.05$ versus control; unpaired $t$ test. Control group, $n=9$; stress group, $n=12$. Data are means \pm the standard error of the mean (SEM). 
traits and behavioral invigoration in mice. In our experiments, these changes were accompanied by a significant increase in the number of attacks by stressed mice in the resident-intruder paradigm, which is an indicator of enhanced aggressive traits (Figure 1E). This is in agreement with previous work showing that increased anxiety levels typically correlate with increased scores of aggressive behavior in C57BL/6J male mice (Willner, 2005).

In line with our findings, different chronic stress procedures have been reported to cause an increase in time spent in anxiety-related compartments of the elevated plus maze and the dark/light box in rodents, which was interpreted as a sign of "anxiolytic-like" effects (Cancela et al., 1995; D'Aquila et al., 1994; Hata et al., 2001; Sanchez, 1997). Such phenomena, also considered as manifestations of impulsivity and disinhibition, are well-known consequences of chronic stress in rodents (Belujon \& Grace, 2011; Strekalova et al., 2005; Willner, 2005). It is commonly accepted that the limbic system, in general, and the hippocampus, in particular, have a central role in the behavioral inhibition system (Abela \& Chudasama, 2013; Geissler \& Lesch, 2011; Gray \& McNaughton, 1983; McNaughton et al., 1997; McNaughton \& Gray, 2000; Rawlins et al., 1985), while the crucial role of the hippocampus for memory was established much earlier (Squire, 1992). Behavioral invigoration, such as during stress, is likely to be associated with alterations of other hippocampal functions, which may include learning processes and molecular changes related to gene expression regulating glutamatergic neurotransmission (Belujon \& Grace, 2011; Calabrese et al., 2012; Geissler \& Lesch, 2011). Thus, these potential changes were investigated in the present study.

Stressed mice had a normal acquisition of the short-term step-down avoidance task, a form of cortex-dependent learning, which was shown by their unaltered latencies to step-down (Figure 2A). However, a lower percentage of freezing during the recall session of the fear-conditioning test in stressed mice indicates a deficiency in their long-term hippocampus-dependent memory (Figure 2B). The possibility that a hyperactivity of chronically stressed mice in our study interferes with scoring of freezing was largely ruled out by a lack of differences in locomotor activity during a 2-min acclimatization pre-training period between stressed and control mice (Strekalova et al., 2003). Also, both groups had similar values for the baseline latencies of step-down behavior (Figure 2A), indicating similar anxiety-like traits when assessed under the testing conditions that were subsequently used to assess contextual learning. Baseline stepdown behavior was previously reported as a highly sensitive measure of subtle changes in anxiety and locomotion in C57BL/6J mice (Strekalova \& Steinbusch, 2009, 2010; Vignisse et al., 2011, 2013).

The changes in contextual freezing significantly correlated with decreased burrowing behavior, although burrowing parameters were not altered significantly (Figure 2C). A tendency to displace food pellets is often regarded as not a fully specific indicator of hippocampal dysfunction in rodents (Hart et al., 2012; Kaczmarczyk et al., 2013; Tarr et al., 2012) and its neurobiology is debatable. Hence the finding of a correlation between this behavior and hippocampus-dependent learning in the present study might be potentially important in relating the burrowing behavior to the dorsal hippocampus, as originally proposed (Deacon et al., 2002).

This study revealed stress-induced increases in the hippocampal expression of NR2A and the NR2A/NR2B ratio (Figure 3A, C), which were previously shown to accompany elevated anxiety (Boyce-Rustay \& Holmes, 2006; Calabrese et al., 2012; Gao et al., 2010), impulsivity and aggression (Bortolato et al., 2012; Meyer et al., 2004), home cage hyperactivity and a stress-induced increase in peripheral concentrations of corticosterone (Huang et al., 2010; Longordo et al., 2009) in various conditions. A limitation of our study, however, is the need for confirmation that the mRNA changes result in corresponding changes in subunit protein levels and in altered synaptic function in the hippocampus. In agreement with our data, separate studies have reported that molecular changes such as we found are associated with a disruption of long-term memory, but not short-term learning (Calabrese et al., 2012; Cui et al., 2013; Huang et al., 2010). In the present experiment, mRNA expression of NR2B and the NR1 in the hippocampus was not significantly changed by stress (Figure 3 ). However, previous work has reported a significant decrease in NR2B expression in several brain areas during stress (Cull-Candy et al., 2001; Huang et al., 2010), aging (Dere et al., 2003) and compromised plasticity (Bortolato et al., 2012). Previous work has also reported a decrease in NR1 mRNA after stress (Cull-Candy et al., 2001; Schenberg et al., 2006). Discrepancies between our findings and others may be due to the different stress paradigms employed. However, previous work we have done in a gene expression profiling Illumina study (Integragen, Evry, France and Northwestern Chicago University, USA and Ingenuity Systems, Redwood city, CA), using hippocampi obtained in a similar chronic stress model (Strekalova et al., 2011), suggests diminished expression of NR1 receptor subunit mRNA in stressed mice in particular, and speaks for systemic differences in the hippocampal glutamatergic receptors expression in these mice in general. In addition to NR1 expression results, these microarray data pointed to statistically significant changes in several elements of the glutamatergic system in the hippocampal formation of chronically stressed mice: NR2B receptor, AMPA receptor, glutamate metabotropic receptor 5 and in NR2A/NR2B ratio, which changes are overall in line with the outcome from mRNA evaluation in the current study. Remarkably, a segregation of stress-susceptible and stress-resilient individuals in the microarray study revealed differential expression of the above genes between the sub-groups that additionally supports functional importance of molecular changes in response to stress, obtained both in the microarray and mRNA experiments

In summary, this study demonstrates that elevated hippocampal expression in stressed mice of mRNAs for NR2A and of the NR2A/NR2B ratio, but not for NR2B and NR1, is associated with concomitant abnormalities in both cognitive and emotional elements that mimic one of the most characteristic consequences of experiencing chronic stress in humans. These data suggest that a paradigm comprising ethological stressors evokes behavioral disinhibition and molecular changes that likely mimic epidemiologically 
spread human syndromes associated with stress-related emotional and cognitive deficits. Thus, the stress paradigm employed in the present study can be useful for translational studies in the search for pharmacological compensation of these combined symptoms of stress-related pathologies.

\section{Declaration of interest}

We thank FP7 (AGGRESSOTYPE), ISAO 9051 to TS, RFBR 11-04-1411 as well as Dr. Claudia Oliveira (CBA, Lisbon University) and Prof. Klimenko (RAS) for supporting this study. J.P. holds a Chargé de Recherche position with Fonds de la Recherche Scientifique. All other authors declare that they have no conflicts of interest.

\section{References}

Abela AR, Chudasama Y. (2013). Dissociable contributions of the ventral hippocampus and orbitofrontal cortex to decision-making with a delayed or uncertain outcome. Eur J Neurosci 37:640-7.

Belujon P, Grace AA. (2011). Hippocampus, amygdala, and stress: interacting systems that affect susceptibility to addiction. Ann N Y Acad Sci 1216:114-21.

Bortolato M, Godar SC, Melis M, Soggiu A, Roncada P, Casu A, Flore G, et al. (2012). NMDARs mediate the role of monoamine oxidase A in pathological aggression. J Neurosci 32:8574-82.

Boyce-Rustay JM, Holmes A. (2006). Genetic inactivation of the NMDA receptor NR2A subunit has anxiolytic- and antidepressant-like effects in mice. Neuropsychopharmacology 31:2405-14.

Calabrese F, Guidotti G, Molteni R, Racagni G, Mancini M, Riva MA. (2012). Stress-induced changes of hippocampal NMDA receptors: modulation by duloxetine treatment. PLoS One 7:e37916.

Cancela LM, Bregonzio C, Molina VA. (1995). Anxiolytic-like effect induced by chronic stress is reversed by naloxone pretreatment. Brain Res Bull 36:209-13.

Cline BH, Steinbusch HW, Malin D, Revishchin AV, Pavlova GV, Cespuglio R, Strekalova T. (2012). The neuronal insulin sensitizer dicholine succinate reduces stress-induced depressive traits and memory deficit: possible role of insulin-like growth factor 2 . BMC Neurosci 13:110.

Couch Y, Anthony DC, Dolgov O, Revischin A, Festoff B, Santos AI, Steinbusch HW, Strekalova T. (2013). Microglial activation, increased TNF and SERT expression in the prefrontal cortex define stressaltered behaviour in mice susceptible to anhedonia. Brain Behav Immun 29:136-46.

Cui Z, Feng R, Jacobs S, Duan Y, Wang H, Cao X, Tsien JZ. (2013). Increased NR2A:NR2B ratio compresses long-term depression range and constrains long-term memory. Sci Rep 3:1036.

Cull-Candy S, Brickley S, Farrant M. (2001). NMDA receptor subunits: diversity, development and disease. Curr Opin Neurobiol 11:327-35.

D’Aquila P, Brain P, Willner P. (1994). Effects of chronic mild stress on performance in behavioral tests relevant to anxiety and depression. Physiol Behav 56:861-7.

Davies DJ, Crowe M, Lucas N, Quinn J, Miller DD, Pritchard S, Grose D, et al. (2012). A novel series of benzimidazole NR2B-selective NMDA receptor antagonists. Bioorg Med Chem Lett 22:2620-3.

Deacon RM, Croucher A, Rawlins JN. (2002). Hippocampal cytotoxic lesion effects on species-typical behaviours in mice. Behav Brain Res 132:203-13.

Dere E, Topic B, De Souza Silva MA, Fink H, Buddenberg T, Huston JP. (2003). NMDA-receptor antagonism via dextromethorphan and ifenprodil modulates graded anxiety test performance of C57BL/6 mice. Behav Pharmacol 14:245-9.

Fleischmann A, Hvalby O, Jensen V, Strekalova T, Zacher C, Layer LE, Kvello A, et al. (2003). Impaired long-term memory and NR2A-type NMDA receptor-dependent synaptic plasticity in mice lacking c-Fos in the CNS. J Neurosci 23:9116-22.

Gao C, Gill MB, Tronson NC, Guedea AL, Guzmán YF, Huh KH, Corcoran KA, et al. (2010). Hippocampal NMDA receptor subunits differentially regulate fear memory formation and neuronal signal propagation. Hippocampus 20:1072-82.
Geissler J, Lesch KP. (2011). A lifetime of attention-deficit/hyperactivity disorder: diagnostic challenges, treatment and neurobiological mechanisms. Expert Rev Neurother 11:1467-84.

Gray JA, McNaughton N. (1983). Comparison between the behavioural effects of septal and hippocampal lesions: a review. Neurosci Biobehav Rev 7:119-88.

Hart AD, Wyttenbach A, Perry VH, Teeling JL. (2012). Age related changes in microglial phenotype vary between CNS regions: grey versus white matter differences. Brain Behav Immun 26:754-65.

Hata T, Nishikawa H, Itoh E, Funakami Y. (2001). Anxiety-like behavior in elevated plus-maze in repeatedly cold stressed mice. Jpn J Pharmacol 85:189-96.

Huang Y, Shi X, Xu H, Yang H, Chen T, Chen S, Chen X. (2010). Chronic unpredictable stress before pregnancy reduce the expression of BDNF and NMDAr in hippocampus of offspring rats associated with impairment of memory. Neurochem Res 35:1038-49.

Kaczmarczyk MM, Machaj AS, Chiu GS, Lawson MA, Gainey SJ, York JM, Meling DD, et al. (2013). Methylphenidate prevents high-fat diet (HFD)-induced learning/memory impairment in juvenile mice. Psychoneuroendocrinology 38:1553-64.

Li F, Tsien JZ. (2009). Memory and the NMDA receptors. N Engl J Med $361: 302-3$

Li ST, Ju JG. (2012). Functional roles of synaptic and extrasynaptic NMDA receptors in physiological and pathological neuronal activities. Curr Drug Targets 13:207-21.

Livak KJ, Schmittgen TD. (2001). Analysis of relative gene expression data using real-time quantitative PCR and the 2(-delta delta $\mathrm{C}(\mathrm{T})$ ) method. Methods 25(4):402-8.

Longordo F, Kopp C, Mishina M, Luján R, Lüthi A. (2009). NR2A at CA1 synapses is obligatory for the susceptibility of hippocampal plasticity to sleep loss. J Neurosci 29:9026-41.

Malatynska E, Steinbusch HW, Redkozubova O, Bolkunov A, Kubatiev A, Yeritsyan NB, Vignisse J, et al. (2012). Anhedonic-like traits and lack of affective deficits in 18-month-old C57BL/6 mice: implications for modeling elderly depression. Exp Gerontol 47: 552-64.

McNaughton N, Gray JA. (2000). Anxiolytic action on the behavioural inhibition system implies multiple types of arousal contribute to anxiety. J Affect Disord 61:161-76.

McNaughton NC, Leach MJ, Hainsworth AH, Randall AD. (1997). Inhibition of human $\mathrm{N}$-type voltage-gated $\mathrm{Ca} 2+$ channels by the neuroprotective agent BW619C89. Neuropharmacology 36:1795-8.

Meyer WN, Korzan WJ, Summers CH. (2004). Social stress and corticosterone regionally upregulate limbic N-methyl-D-aspartatereceptor (NR) subunit type NR(2A) and NR(2B) in the lizard Anolis carolinensis. Neuroscience 128:675-84.

Pawluski JL, Valença A, Santos AI, Costa-Nunes JP, Steinbusch HW, Strekalova T. (2012). Pregnancy or stress decrease complexity of CA3 pyramidal neurons in the hippocampus of adult female rats. Neuroscience 227:201-10.

Rawlins JN, Feldon J, Ursin H, Gray JA. (1985). Resistance to extinction after schedules of partial delay or partial reinforcement in rats with hippocampal lesions. Exp Brain Res 59:273-81.

Sanchez C. (1997). Acute stress enhances anxiolytic-like drug responses of mice tested in a black and white test box. Eur Neuropsychopharmacol 7:283-8.

Schenberg EE, Ferreira TL, Figueiredo LZ, Hipólide DC, Nóbrega JN, Oliveira MG. (2006). Fear conditioning and NMDA receptor subtypes: NR2A differential expression in the striatum. Brain Res Bull 69:440-6.

Squire LR. (1992). Memory and the hippocampus: a synthesis from findings with rats, monkeys, and humans. Psychol Rev 99: $195-231$.

Strekalova T, Couch Y, Kholod N, Boyks M, Malin D, Leprince P, Steinbusch HWM. (2011). Update in the methodology of the chronic stress paradigm: internal control matters. Behav Brain Funct 7:9.

Strekalova T, Spanagel R, Bartsch D, Henn FA, Gass P. (2004). Stress-induced anhedonia in mice is associated with deficits in forced swimming and exploration. Neuropsychopharmacology 29: 2007-17.

Strekalova T, Spanagel R, Dolgov O, Bartsch D. (2005). Stress-induced hyperlocomotion as a confounding factor in anxiety and depression models in mice. Behav Pharmacol 16:171-80. 
Strekalova T, Steinbusch H. (2009). Factors of reproducibility of stressinduced anhedonia in chronic stress depression models in mice. In: Gould T, editor. Mood and anxiety related phenotypes in mice: characterization using behavioral tests. Totowa, NJ: Humana Press. p 153-76.

Strekalova T, Steinbusch HW. (2010). Measuring behavior in mice with chronic stress depression paradigm. Prog Neuropsychopharmacol Biol Psychiatry 34:348-61.

Strekalova T, Wotjak CT, Schachner M. (2001). Intrahippocampal administration of an antibody against the HNK-1 carbohydrate impairs memory consolidation in an inhibitory learning task in mice. Mol Cell Neurosci 17:1102-13.

Strekalova T, Zörner B, Zacher C, Sadovska G, Herdegen T, Gass P. (2003). Memory retrieval after contextual fear conditioning induces c-Fos and JunB expression in CA1 hippocampus. Genes Brain Behav 2:3-10.

Tarr AJ, Chen Q, Wang Y, Sheridan JF, Quan N. (2012). Neural and behavioral responses to low-grade inflammation. Behav Brain Res 235:334-41.
Tsang SW, Vinters HV, Cummings JL, Wong PT, Chen CP, Lai MK. (2008). Alterations in NMDA receptor subunit densities and ligand binding to glycine recognition sites are associated with chronic anxiety in Alzheimer's disease. Neurobiol Aging 29:1524-32.

Vignisse J, Steinbusch HW, Bolkunov A, Nunes J, Santos AI, Grandfils C, Bachurin S, Strekalova T. (2011). Dimebon enhances hippocampus-dependent learning in both appetitive and inhibitory memory tasks in mice. Prog Neuropsychopharmacol Biol Psychiatry 35:510-22.

Vignisse J, Steinbusch HWM, Grigoriev V, Bolkunov A, Proshin A, Bettendorff L, Bachurin S, Strekalova T. (2013). Concomitant manipulation of NMDA- and AMPA-receptors to produce procognitive drug effects in mice. Eur Neuropsychopharmacol. [Epub ahead of print]. doi: 10.1016/j.euroneuro.2013.06.010.

Willner P. (2005). Chronic mild stress (CMS) revisited: consistency and behavioural neurobiological concordance in the effects of CMS. Neuropsychobiology 52:90-110. 